\title{
Novel GATA6 loss-of-function mutation responsible for familial atrial fibrillation
}

\author{
JIAN LI $^{1 *}$, WEI-DONG LIU ${ }^{2 *}$, ZHONG-LIANG YANG ${ }^{1}$ and YI-QING YANG ${ }^{3}$ \\ Departments of ${ }^{1}$ Emergency and ${ }^{2}$ Neurosurgery, Pu Nan Hospital, Shanghai 200125; ${ }^{3}$ Department of Cardiovascular Research, \\ Shanghai Chest Hospital, Medical College of Shanghai Jiaotong University, Shanghai 200030, P.R. China
}

Received April 21, 2012; Accepted June 19, 2012

DOI: $10.3892 /$ ijmm.2012.1068

\begin{abstract}
Atrial fibrillation (AF) is the most commonly sustained cardiac arrhythmia, and confers a substantially increased risk of morbidity and mortality. Increasing evidence has indicated that hereditary defects are implicated in AF. However, AF is genetically heterogeneous and the genetic etiology of AF in a significant portion of patients remains unclear. In this study, the entire coding sequence and splice junctions of the GATA6 gene, which encodes a zinc-finger transcription factor crucial for cardiogenesis, were sequenced in 140 unrelated patients with lone AF. The available relatives of the index patient carrying an identified mutation and 200 unrelated ethnically-matched healthy individuals used as the controls were genotyped. The functional characteristics of the mutant GATA6 were assessed in contrast to its wild-type counterpart using a luciferase reporter assay system. As a result, a novel heterozygous GATA6 mutation, p.G469V, was identified in a family with AF inherited in an autosomal dominant pattern. The mutation was absent in the 200 control individuals and the altered amino acid was completely conserved across species. Functional analysis demonstrated that the GATA6 mutation was associated with a significantly decreased transcriptional activity. The findings provide novel insight into the molecular mechanism involved in the pathogenesis of AF, as well as insight into potential therapies for the prevention and treatment of AF.
\end{abstract}

Correspondence to: Dr Wei-Dong Liu, Department of Neurosurgery, Pu Nan Hospital, Pu Dong, 2400 South Pudong Road, Shanghai 200125, P.R. China

E-mail: liuweidong96@126.com

Dr Yi-Qing Yang, Department of Cardiovascular Research, Shanghai Chest Hospital, Medical College of Shanghai Jiaotong University, 241 West Huaihai Road, Shanghai 200030, P.R. China

E-mail: yang99yang66@hotmail.com

*Contributed equally

Key words: atrial fibrillation, genetics, transcription factor, GATA6

\section{Introduction}

Atrial fibrillation (AF) is the most common type of sustained cardiac arrhythmia, accounting for approximately $1 / 3$ of hospitalizations for heart rhythm disorders (1). The prevalence of $\mathrm{AF}$ is approximately $1 \%$ in the general population, and is drastically increasing with advancing age, rising from approximately $0.1 \%$ in individuals younger than 55 years of age up to almost $10 \%$ in those aged 80 years and older (2). The lifetime risk of developing AF is estimated to be $25 \%$ for both men and women over 40 years of age (3). AF confers a substantially increased risk of morbidity and mortality. It increases the risk of stroke by 3 - to 5-fold, causing a huge economic burden on the health care system and an adverse impact on the quality of life of patients (4). Compared to subjects with sinus rhythm, patients with AF have a 2-fold increased risk of mortality (5). Additionally, AF can also result in other complications, such as adverse hemodynamics, impaired cognitive function or dementia, congestive heart failure and tachycardia-induced cardiomyopathy (6). AF is frequently observed as a complication of various cardiac and systemic conditions, including hypertension, coronary artery disease, valvular heart disease, cardiomyopathies and metabolic disorders. Hence, AF is traditionally regarded as an acquired disorder (1). However, in $30-45 \%$ of $\mathrm{AF}$ patients, an underlying cause cannot be identified by routine procedures, and such AF is defined as 'idiopathic' or 'lone' (1), of which at least $15 \%$ of patients have a positive family history, so termed familial AF (7). Growing evidence has substantiated the familial aggregation of $\mathrm{AF}$ and an increased susceptibility to AF in the close relatives of patients with AF, highlighting the fact that genetic factors play a role in the pathogenesis of AF in a subset of cases (8-14). Studies on human and medical genetics have revealed multiple AF-related genes, including KCNQ1, KCNE2, SCN5A, KCNH2, KCNJ2, GJA5, KCNA5, KCNE3, KCNE5, NPPA, NUP155, $S C N 1 B, S C N 2 B, S C N 3 B$ and GJAl (15-29). In addition, 4 chromosomal loci linked to AF have been mapped, although the AF-associated genes have not yet been discovered (30-33). Nevertheless, AF is genetically heterogeneous and the genetic determinants for AF in most patients remain unknown (7).

Recently, there is increasing evidence indicating the essential role of several transcription factors, including NKX2-5 and GATA4 in normal cardiogenesis (34-36), and mutations in NKX2-5 and GATA4 have been causally implicated in 
congenital cardiovascular abnormalities and AF (37-44). GATA6 is another member of the GATA family, and its expression and function overlap with those of GATA4 during cardiac development, particularly in the regulation of target gene expression synergistically with NKX2-5 $(36,45)$, which implies the potential association of functionally impaired GATA6 with AF.

In this study, in order to evaluate the prevalence of GATA6 mutations in patients with lone AF and characterize the mechanism by which mutated GATA6 predisposes to AF, the coding exons and exon/intron boundaries of GATA6 were sequenced in patients with lone AF in contrast to healthy individuals, and the functional characteristics of the mutant GATA6 were analyzed in comparison with its wild-type counterpart using a luciferase reporter assay system.

\section{Materials and methods}

Study participants. A total of 140 unrelated patients with lone AF were identified among the Han Chinese population. The controls were 200 ethnically-matched unrelated healthy individuals. Peripheral venous blood samples were prepared and clinical data including medical records, electrocardiogram and echocardiography reports were collected. The study subjects were clinically classified using a consistently applied set of definitions $(7,43)$. Briefly, the diagnosis of AF was made by a standard 12-lead electrocardiogram demonstrating no $\mathrm{P}$ waves and irregular R-R intervals regardless of the clinical symptoms. Lone AF was defined as AF occurring in individuals $<60$ years of age without other cardiac or systemic diseases by physical examination, electrocardiogram, transthoracic echocardiogram, and extensive laboratory tests. Familial AF was defined as the presence of documented lone $\mathrm{AF}$ in 2 or more 1st- or 2nd-degree relatives. Relatives with AF occurring at any age in the setting of structural heart disease (hypertensive, ischemic, myocardial or valvular) were classified as 'undetermined' for having an inherited form of AF. The 'undetermined' classification was also used if the documentation of AF on an electrocardiogram tracing was lacking in relatives with symptoms consistent with AF (palpitations, dyspnea and light-headedness), or if a screening electrocardiogram and echocardiogram were not performed, irrespective of the symptoms. Relatives were classified as 'unaffected' if they were asymptomatic and had a normal electrocardiogram. Paroxysmal AF was defined as AF lasting for $>30 \mathrm{sec}$ that terminated spontaneously. Persistent AF was defined as AF lasting for $>7$ days and requiring either pharmacological therapy or electrical cardioversion for termination. AF that was refractory to cardioversion or that was allowed to continue was classified as permanent. The study protocol was reviewed and approved by the local institutional ethics committee and written informed consent was obtained from all participants prior to investigation.

Genetic studies. Genomic DNA from all participants was extracted from blood lymphocytes with the Wizard ${ }^{\circledR}$ Genomic DNA Purification kit (Promega, Madison, WI, USA). Initially, the whole coding sequence and splice junctions of the GATA6 gene were screened in 140 unrelated patients with lone AF. Subsequently, genotyping of GATA6 was performed in the available relatives of the index patient carrying an identified mutation and 200 ethnically-matched unrelated healthy individuals used as the controls. The referential genomic DNA sequence of GATA6 was derived from GenBank (accession no. NT_010966). With the help of online Primer 3 software (http://frodo.wi.mit.edu), the primer pairs used to amplify the coding exons (exons 2-7) and intron-exon boundaries of GATA6 by polymerase chain reaction (PCR) were designed as shown in Table I. PCR was carried out using HotStarTaq DNA Polymerase (Qiagen, Hilden, Germany) on a PE 9700 Thermal Cycler (Applied Biosystems, Foster City, CA, USA) with standard conditions and concentrations of reagents. Amplified products were purified with the QIAquick Gel Extraction kit (Qiagen). Both strands of each PCR product were sequenced with a BigDye ${ }^{\circledR}$ Terminator v3.1 Cycle Sequencing kit (Applied Biosystems) under an ABI PRISM 3130XL DNA Analyzer (Applied Biosystems). The sequencing primers were those designed previously for specific region amplifications. DNA sequences were viewed and analyzed with the DNA Sequencing Analysis Software v5.1 (Applied Biosystems). The variant was validated by resequencing of an independent PCR-generated amplicon from the subject and met our quality control threshold with a call rate exceeding $99 \%$.

Alignment of multiple GATA6 protein sequences across species. The multiple GATA6 protein sequences across various species were aligned using the software ClustalW version 2.0 (an interactive program at http://www.ebi.ac.uk/Tools/msa/ clustalw2/).

Plasmids and site-directed mutagenesis. The recombinant expression plasmid pcDNA3-hGATA6 was kindly provided by Dr Angela Edwards-Ghatnekar, from the Division of Rheumatology and Immunology, Medical University of South Carolina, Charleston, SC, USA. The atrial natriuretic factor (ANF)-luciferase reporter gene, which contains the 2600-bp 5 '-flanking region of the $A N F$ gene, namely ANF(-2600)-Luc, was kindly provided by Dr Ichiro Shiojima, from the Department of Cardiovascular Science and Medicine, Chiba University Graduate School of Medicine, Chiba, Japan. The identified mutation was introduced into the wild-type GATA6 using a QuikChange II XL Site-Directed Mutagenesis kit (Stratagene, La Jolla, CA, USA) with a complementary pair of primers. The mutant was sequenced to confirm the desired mutation and to exclude any other sequence variations.

Reporter gene assays. HEK-293 cells were cultured in Dulbecco's modified Eagle's medium supplemented with $10 \%$ fetal calf serum. The ANF(-2600)-Luc reporter construct and an internal control reporter plasmid [pGL4.75 (hRluc/CMV), Promega] were used in transient transfection assays to examine the transcriptional activation function of the GATA6 mutant. HEK-293 cells were transfected with $0.4 \mu \mathrm{g}$ of wild-type or mutant pcDNA3-hGATA6 expression vector, $0.4 \mu \mathrm{g}$ of ANF(-2600)-Luc reporter construct, and $0.04 \mu \mathrm{g}$ of pGL4.75 control reporter vector using PolyFect Transfection Reagent (Qiagen). For co-transfection experiments, $0.2 \mu \mathrm{g}$ of wild-type pcDNA3-hGATA6, $0.2 \mu \mathrm{g}$ of mutant pcDNA3-hGATA6, $0.4 \mu \mathrm{g}$ of ANF(-2600)-Luc and $0.04 \mu \mathrm{g}$ of pGL4.75 were used. Firefly luciferase and Renilla luciferase activities were measured with 
Table I. The intronic primers used to amplify the coding exons and exon-intron boundaries of GATA6.

\begin{tabular}{lllc}
\hline Exon & \multicolumn{1}{c}{ Forward primer (5' to 3') } & \multicolumn{1}{c}{ Reverse primer (5' to 3') } & Amplicon (bp) \\
\hline 2-a & TTG, TTA, ACC, CGT, CGA, TCT, CC & GCG, AGG, GTC, TGG, TAC, ATC, TC & 543 \\
2-b & TGC, TGT, TCA, CTG, ACC, TCG, AC & CTG, GGA, GAG, TAG, GGG, AAG, C & 466 \\
2-c & CCG, ACA, GCC, CTC, CAT, ACG & GAA, AAC, AGG, GCC, CGA, GTG & 539 \\
3 & GGC, CAA, GGA, GAA, AAG, CTC, AG & GTT, GGA, ACA, GCC, GGG, ACA, G & 485 \\
4 & TCT, TGG, CCC, AGA, AAA, GTC, AG & TCA, TTT, GCT, GAT, TCT, TTG, TAA, CTG & 387 \\
5 and 6 & CTG, GGA, TTA, GAG, GCG, TGA, GC & TTT, ACT, AGA, GAG, CAG, CCC, AGT & 473 \\
7 & ATT, TCT, CCT, GCC, CTG, GGT, CT & CTG, CAC, AAA, AGC, AGA, CAC, GA & 382 \\
\hline
\end{tabular}

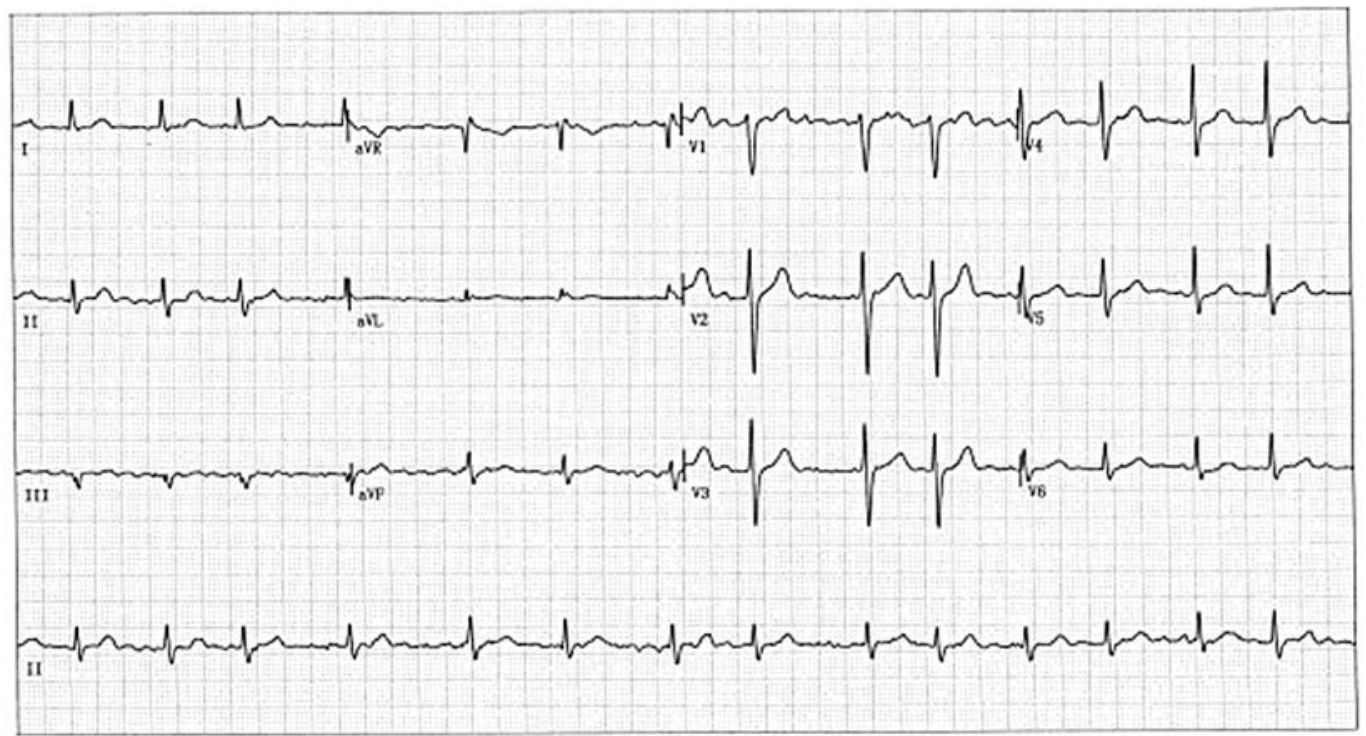

Figure 1. Standard 12-lead surface electrocardiogram of the proband (II-2). The electrocardiogram illustrates atrial fibrillation.

the Dual-Glo ${ }^{\circledR}$ luciferase assay system (Promega) $48 \mathrm{~h}$ after transfection. A minimum of 3 independent experiments were performed for wild-type and mutant GATA6.

Statistical analysis. Data are expressed as the means \pm SD. Continuous variables were examined for normality of distribution and the Student's unpaired t-test was used for the comparison of numeric variables between 2 groups. A comparison of the categorical variables between 2 groups was performed using Pearson's $\chi^{2}$ test or Fisher's exact test when appropriate. A two-tailed P-value $<0.05$ was considered to indicate a statistically significant difference.

\section{Results}

Characteristics of the study subjects. A total of 140 unrelated patients with lone AF and a cohort of 200 ethnically-matched unrelated healthy individuals used as the controls were recruited and clinically evaluated. None of them had overt traditional risk factors for AF. There were no significant differences between the patient and control groups in baseline characteristics including age, gender, body mass index, blood pressure, fasting blood glucose and serum lipid levels, left atrial dimension, left ventricular ejection fraction, heart rate at rest, as well as lifestyle (data not shown). At the time of the present study, 12 patients were also diagnosed with hypertension in accordance with the criterion that the average systolic or diastolic blood pressure ( 2 readings made after 5 min of rest in the sitting position) was $\geq 140$ or $\geq 90 \mathrm{~mm} \mathrm{Hg}$, respectively, but at the time of the initial diagnosis of AF, their blood pressures were normal. The baseline clinical characteristics of the 140 patients with lone AF are summarized in Table II.

GATA6 mutation. Direct sequencing of the coding exons and exon-intron boundaries of the GATA6 gene was carried out after PCR amplification of genomic DNA from each of the 140 patients with lone AF. A heterozygous GATA6 mutation was identified in $1 / 140$ unrelated patients, with a prevalence of approximately $1.71 \%$ for GATA6 mutation. Specifically, A substitution of $\mathrm{T}$ for $\mathrm{G}$ in the second nucleotide of codon 469 (c.1406G $>$ T), predicting the transition of glycine $(\mathrm{G})$ into valine (V) at amino acid 469 (p.G469V) was identified in a patient with a positive family history. A representative 12-lead electrocardiogram of the index patient with AF is recorded in Fig. 1. The sequence chromatograms showing the detected heterozygous GATA6 sequence mutation of c. $406 \mathrm{G}>\mathrm{T}$ compared with 
Table II. The baseline clinical characteristics of the 140 patients with lone atrial fibrillation.

\begin{tabular}{lcc}
\hline Parameter & No. or quantity & Percentage or range \\
\hline Male & 78 & 56 \\
Age at first diagnosis of atrial fibrillation (years) & 48.56 & $21-59$ \\
Type of atrial fibrillation at presentation & & 66 \\
Paroxysmal & 92 & 25 \\
Persistent & 35 & 9 \\
Permanent & 13 & 32 \\
Positive family history of atrial fibrillation & 45 & 41 \\
Underwent cardioversion & 58 & 7 \\
Cardiac pacemaker installed & 10 & $48-162$ \\
Resting heart rate (bpm) & 76.14 & $92-138$ \\
Systolic blood pressure (mmHg) & 128.04 & $65-88$ \\
Diastolic blood pressure (mmHg) & 82.36 & $20-24$ \\
Body mass index (kg/m $\left.{ }^{2}\right)$ & 22.24 & $31-46$ \\
Left atrial diameter (mm) & 37.90 & $50-72$ \\
Left ventricular ejection fraction (\%) & 62 & $4-6$ \\
Fasting blood glucose (mmol/l) & 4.52 & $3-5$ \\
Total cholesterol (mmol/l) & 3.71 & $1-2$ \\
Triglycerides (mmol/l) & 1.24 & 69 \\
Medications & & 23 \\
Amiodarone & 96 & 46 \\
Aspirin & 32 & 20 \\
Warfarin & 64 & 12 \\
Calocker & 28 & 25 \\
Digoxin & 17 & \\
& 35 & \\
& & \\
& &
\end{tabular}

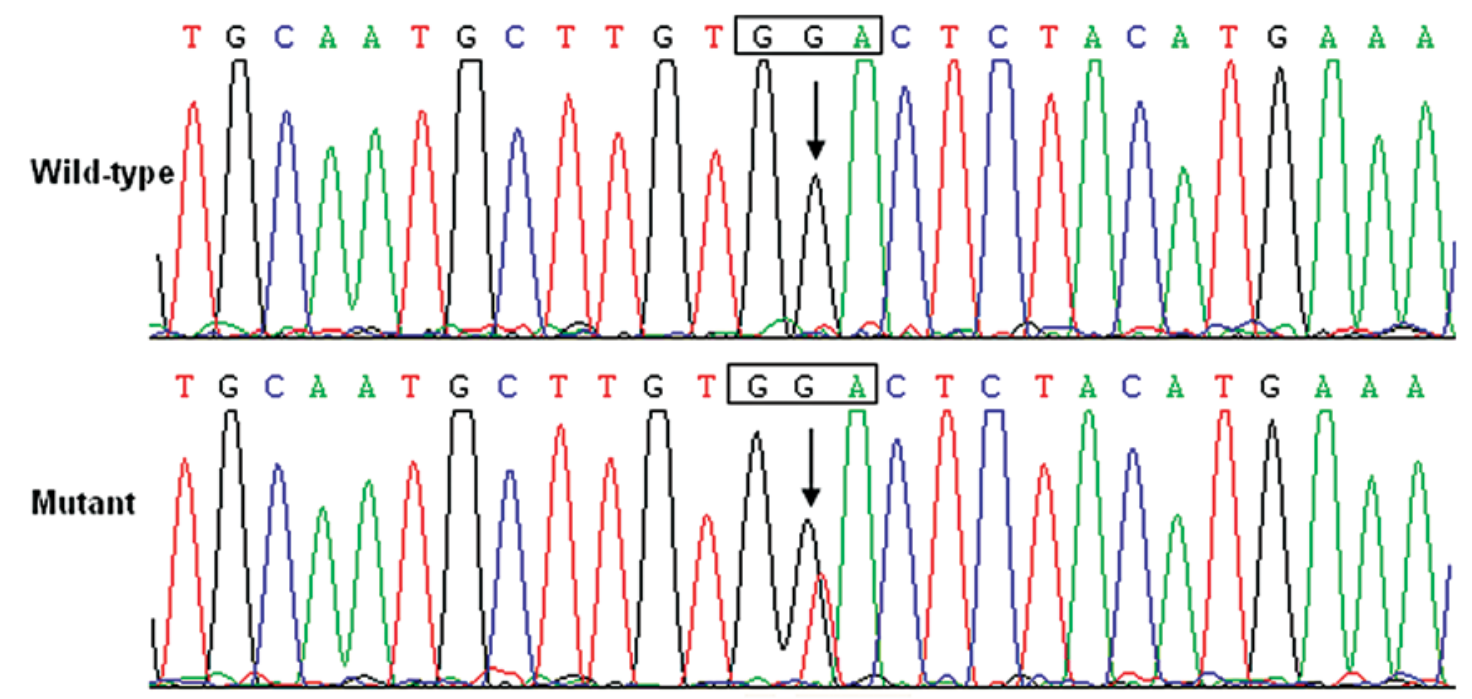

Figure 2. Sequence electropherograms of GATA6 in the proband and a control individual. The arrow indicates the heterozygous nucleotides of G/T in the proband (mutant) or the homozygous nucleotides of G/G in a control individual (wild-type). The square denotes the nucleotides comprising a codon of GATA6.

the corresponding control sequence are shown in Fig. 2. The missense mutation was not found in either the control population or reported in the SNP database (http://www.ncbi.nlm.
nih.gov/SNP). Genetic scan of the available family members displayed that the mutation was present in all affected living family members, but absent in unaffected family members 


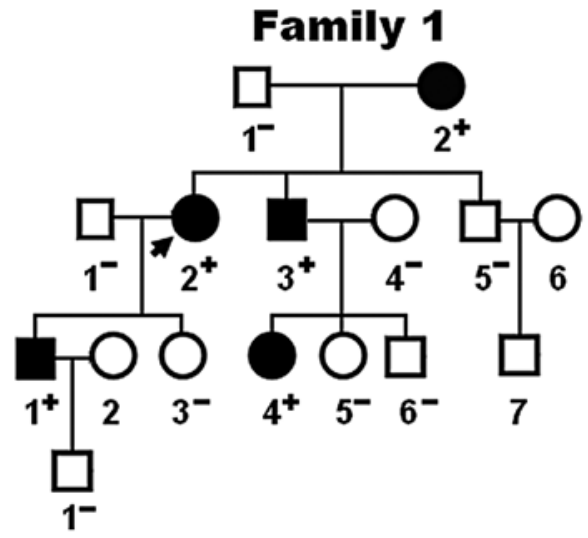

Figure 3. Pedigree structure of the family with atrial fibrillation. Family members are identified by generations and numbers. Squares, male family members; circles, female members; closed symbols, affected members; open symbols, unaffected members; arrow, proband; + , carriers of the heterozygous mutation; and -, non-carriers.

examined. Pedigree analysis demonstrated that the mutation cosegregated with AF transmitted in an autosomal dominant pattern in the family with complete penetrance. The pedigree structure of the family is illustrated in Fig. 3. The phenotypic characteristics and results of genetic screening of the affected family members are listed in Table III. Congenital atrial septal defect was confirmed by medical records of previous catheterbased repairs in 2 AF patients (II-3 and III-4), indicating that $\mathrm{AF}$ may share a common genetic origin with congenital heart disease.

Alignment of multiple GATA6 protein sequences. A crossspecies alignment of GATA6 protein sequences showed that the altered amino acid was completely conserved, as presented in Fig. 4, suggesting that the amino acid is functionally important.

Transcriptional activity of the GATA4 mutants. The transcriptional activation characterization of the mutated GATA6 in HEK-293 cells was examined using one of its direct cardiac downstream target genes, $A N P$, as a luciferase reporter, and the activity of the $A N P$ promoter was presented as the fold activation of Firefly luciferase activity relative to Renilla luciferase activity. Equal amounts of wild-type $(0.4 \mu \mathrm{g})$ and G469V-mutant GATA6 $(0.4 \mu \mathrm{g})$ activated the ANP promoter by $\sim 11$ - and $\sim 2$-fold, respectively. When the same amount of wild-type GATA4 $(0.2 \mu \mathrm{g})$ was co-transfected with G469Vmutant GATA4 $(0.2 \mu \mathrm{g})$, the induced activation of the ANP promoter was $\sim 6$-fold. These results suggest that the GATA6 mutation has a significantly reduced activation activity compared with its wild-type counterpart (Fig. 5).

\section{Discussion}

In the present study, a novel heterozygous GTA6 mutation of p.G469V identified in a family with lone AF is reported. This missense mutation of GATA6 was present in all the affected family members examined but was absent in the unaffected family members available and 400 normal chromosomes from a matched control population. A cross-species alignment of

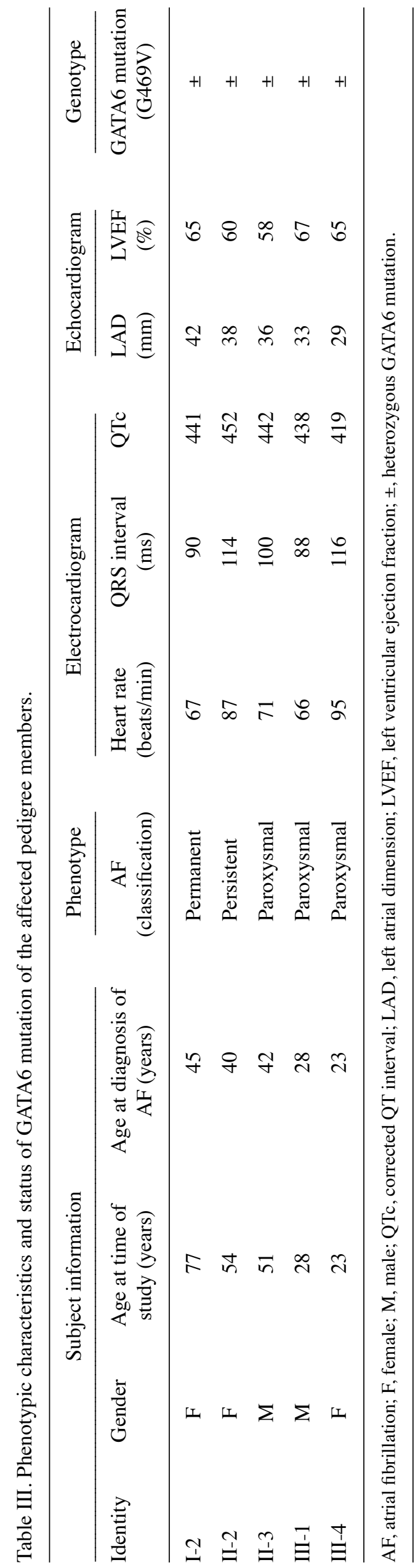




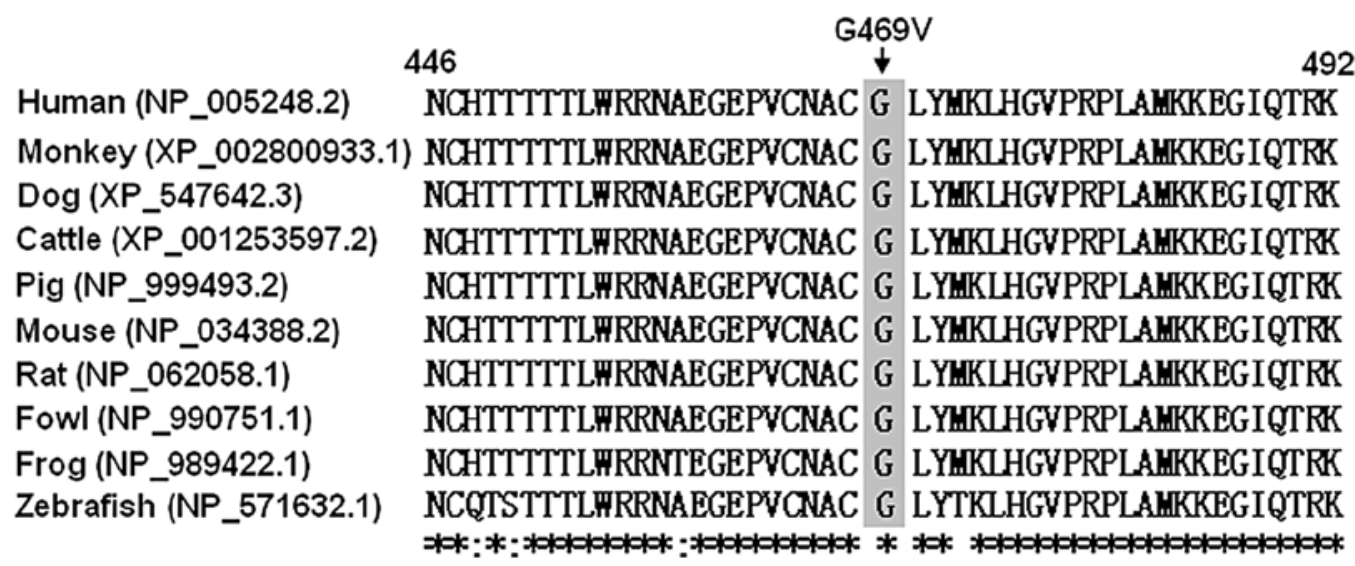

Figure 4. Alignment of multiple GATA6 protein sequences across species. The altered amino acid of p.G469 is completely conserved across species.

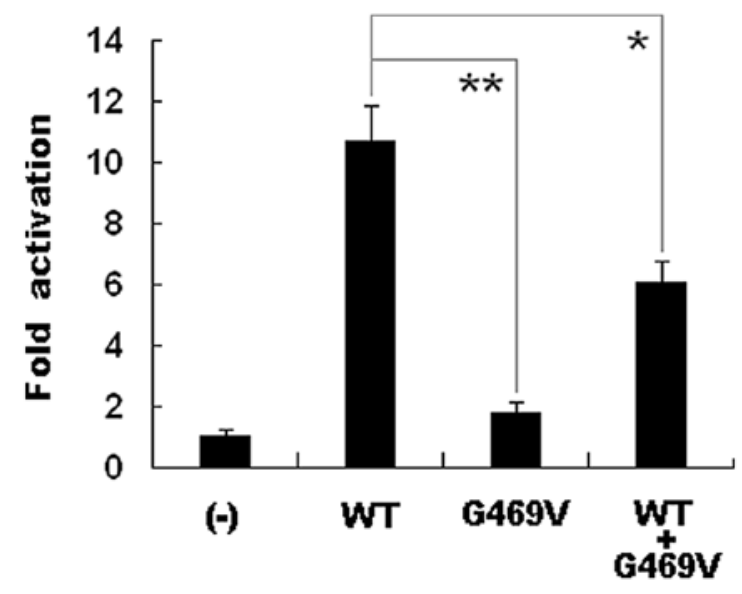

Figure 5. Functional impairments resulted from GATA6 mutation. Activation of ANP-luciferase reporter in HEK-293 cells by GATA6 wild-type (WT) or mutant $(\mathrm{G} 469 \mathrm{~V})$, alone or in combination, demonstrated significantly reduced transactivation by mutant protein. Experiments were performed in triplicate and the mean and standard deviations are shown. ${ }^{\text {"P }}<0.001$ and ${ }^{* *} \mathrm{P}<0.005$, respectively, when compared with wild-type GATA6.

multiple GATA6 protein sequences exhibited that the altered amino acid was completely conserved. Functional analysis demonstrated that the p.G469V mutation of GATA6 was associated with a significantly decreased transcriptional activity. Therefore, it is highly likely that functionally impaired GATA6 is involved in the pathogenesis of AF in this family. To our knowledge, this is the first description of the correlation between a GATA6 loss-of-function mutation and susceptibility to familial AF. These results expand the spectrum of GATA6 mutations linked to $\mathrm{AF}$ and provide significant insight into the molecular basis underlying AF.

GATA transcription factors are a group of DNA binding proteins characteristic of preferential binding to the consensus DNA sequence GATA of target gene promoters. The GATA family comprises 6 members (GATA1-GATA6), of which GATA4, GATA5 and GATA6 are expressed in various mesoderm and endoderm-derived tissues, particularly in the embryonic and adult heart (36). GATA6 maps to human chromosome 18q11.1-q11.2 by fluorescence in situ hybridization, which encodes a predicted 449-amino-acid protein (46).
Functionally, GATA6 consists of 2 transcriptional activation domains (TADs), 2 adjacent zinc fingers (ZFs), and 1 nuclear localization signal (NLS). The 2 TADs are essential for the transcriptional activity of GATA6. The C-terminal ZF is required for DNA sequence recognition and binding to the consensus motif, while the N-terminal ZF is responsible for stability and sequence specificity of protein-DNA binding as well as the transcriptional activation by GATA factors. The majority of the protein-protein interactions of GATA factors are mediated by its C-terminal ZF. The NLS sequence is associated with the subcellular trafficking and distribution of GATA6 (36). The GATA6 mutation, p.G469V, identified in this study is located in the C-terminal ZF; therefore, it may be expected to exert influence on the transcriptional activation of GATA6 by interfering with the binding to the downstream target DNA.

It has been substantiated that GATA6 is an upstream regulator of multiple genes transcribed during embryogenesis and cardiac morphogenesis, including the genes that encode the atrial natriuretic peptide (ANP), brain natriuretic peptide, $\alpha$-myosin heavy chain, $\beta$-myosin heavy chain and cardiac troponin $\mathrm{C}$ and I (36). Hence, the functional characteristics of the GATA6 mutations may be explored by analysis of the transcriptional activity of the ANP promoter in cells transfected with the GATA6 mutant in contrast to its wild-type counterpart. In this study, the functional effect of the novel p.G469V mutation of GATA6 identified in our familial AF patients was characterized by transcriptional activity assays and the results demonstrated a significantly decreased transcriptional activity on a downstream gene, consistent with the loss-of-function effects of other GATA6 mutations underlying congenital cardiovascular malformations on the transcriptional activity of the ANP promoter $(47,48)$. These findings indicate that the haploinsufficiency or loss-of-function effect resulting from GATA6 mutations is potentially an important pathophysiological mechanism involved in AF, although the functional roles of the recently reported AF-related GATA6 mutations remain to be ascertained (49).

The findings that functionally compromised GATA6 confers susceptibility to AF may be partially ascribed to the abnormally developed pulmonary vein myocardium (50-52). The pulmonary venous vessels are ensheathed by a layer of 
myocardium termed pulmonary myocardial sleeve, which has been demonstrated to be responsible for the initiation and perpetuation of AF by several potential arrhythmogenic mechanisms, including intrinsic pacemaker activity and properties facilitating re-entrance (50-52). Genetic labeling lineage-tracing studies have shown that NKX2-5 is expressed in the atrial and pulmonary myocardium and is essential for the localized formation of the sinoatrial node during embryonic development. NKX2-5 can act as a suppressor of the sinoatrial node lineage gene program, which limits pacemaker activity to the sinus and atrioventricular node. When the NKX2-5 protein level was lowered in a hypomorphic model, the pulmonary cardiomyocytes switched to connexin40-negative, HCN4-positive cells, a nodal-like phenotype with pacemaker activity (51). In $N K X 2-5$-deficient mouse embryos, HCN4 was activated in the entire embryonic heart tube, whereas connexin 40 expression was lost, and the ectopic expression of pacemaker cells was observed throughout the heart tube (53). In humans, AF has been reported as an isolated phenotype or a part of compound phenotypes in patients harboring $N K X 2-5$ mutations $(40,54,55)$. Therefore, as a transcriptionally cooperative partner of NKX2-5, GATA6, when a loss-of-function mutation occurs, may conduce to the formation of the pulmonary myocardium sleeve and the shift of the pulmonary myocardium to a sinoatrial node-like phenotype by reducing the expression of NKX2-5, hence producing an atrial electrophysiological substrate favoring AF.

There are a large number of downstream genes transactivated by GATA6, and mutations in several target genes have been associated with AF, including $\beta$-myosin heavy chain, ANP and connexin $40(24,25,56-58)$. Therefore, it is highly likely for mutated GATA6 to predispose to AF by decreasing the expression of target genes.

Of note, congenital atrial septal defect was documented in 2 AF patients carrying the p.G469V mutation of GATA6. Similar to our current findings, congenital cardiac defects were previously confirmed in $3 \mathrm{AF}$ patients carrying heterozygous GATA6 mutations, including atrial septal defect in 1 missense mutation (p.Q206P) carrier and ventricular septal defect in 2 truncation mutation (p.Y265X) carriers (49). These observations suggest that AF may share a common genetic origin with congenital heart disease.

In conclusion, the results from the present study link a novel mutation in the cardiac transcription factor, GATA6, to familial $\mathrm{AF}$ and provides novel insight into the molecular mechanism involved in AF, as well as insight into potential therapies for the prevention and treatment of this common type of arrhythmia.

\section{Acknowledgements}

We are indebted to participants for their dedication to the study. This study was supported in part by grants from the National Natural Science Fund of China (81070153 and 30570768), the National Basic Research Program of China (2010CB912604), the Personnel Development Foundation of Shanghai, China (2010019), the Key Program of Basic Research of Shanghai, China (10JC1414000, 10JC1414001 and 10JC1414002) and the Natural Science Fund of Shanghai, China (10ZR1428000).

\section{References}

1. Fuster V, Rydén LE, Cannom DS, Crijns HJ, Curtis AB, Ellenbogen KA, Halperin JL, Kay GN, Le Huezey JY, Lowe JE, et al; American College of Cardiology Foundation/American Heart Association Task Force: 2011 ACCF/AHA/HRS focused updates incorporated into the ACC/AHA/ESC 2006 guidelines for the management of patients with atrial fibrillation: a report of the American College of Cardiology Foundation/American Heart Association Task Force on practice guidelines. Circulation 123: e269-e367, 2011.

2. Go AS, Hylek EM, Phillips KA, Chang Y, Henault LE, Selby JV and Singer DE: Prevalence of diagnosed atrial fibrillation in adults: national implications for rhythm management and stroke prevention: the AnTicoagulation and Risk Factors in Atrial Fibrillation (ATRIA) Study. JAMA 285: 2370-2375, 2001.

3. Lloyd-Jones DM, Wang TJ, Leip EP, Larson MG, Levy D, Vasan RS, D'Agostino RB, Massaro JM, Beiser A, Wolf PA and Benjamin EJ: Lifetime risk for development of atrial fibrillation: the Framingham Heart Study. Circulation 110: 1042-1046, 2004.

4. Wolf PA, Abbott RD and Kannel WB: Atrial fibrillation as an independent risk factor for stroke: the Framingham Study. Stroke 22: 983-988, 1991.

5. Benjamin EJ, Wolf PA, D'Agostino RB, Silbershatz H Kannel WB and Levy D: Impact of atrial fibrillation on the risk of death: the Framingham Heart Study. Circulation 98: 946-952, 1998.

6. Magnani JW, Rienstra M, Lin H, Sinner MF, Lubitz SA, McManus DD, Dupuis J, Ellinor PT and Benjamin EJ: Atrial fibrillation: current knowledge and future directions in epidemiology and genomics. Circulation 124: 1982-1993, 2011.

7. Darbar D, Herron KJ, Ballew JD, Jahangir A, Gersh BJ, Shen WK, Hammill SC, Packer DL and Olson TM: Familial atrial fibrillation is a genetically heterogeneous disorder. J Am Coll Cardiol 41: 2185-2192, 2003.

8. Ellinor PT, Yoerger DM, Ruskin JN and MacRae CA: Familial aggregation in lone atrial fibrillation. Hum Genet 118: 179-184, 2005.

9. Arnar DO, Thorvaldsson S, Manolio TA, Thorgeirsson G, Kristjansson K, Hakonarson H and Stefansson K: Familial aggregation of atrial fibrillation in Iceland. Eur Heart J 27: 708-712, 2006.

10. Junttila MJ, Raatikainen MJ, Perkiömäki JS, Hong K, Brugada R and Huikuri HV: Familial clustering of lone atrial fibrillation in patients with saddleback-type ST-segment elevation in right precordial leads. Eur Heart J 28: 463-468, 2007.

11. Christophersen IE, Ravn LS, Budtz-Joergensen E, Skytthe A, Haunsoe S, Svendsen JH and Christensen K: Familial aggregation of atrial fibrillation: a study in Danish twins. Circ Arrhythm Electrophysiol 2: 378-383, 2009.

12. Yang YQ, Zhang XL, Wang XH, Tan HW, Shi HF, Fang WY and Liu X: Familial aggregation of lone atrial fibrillation in the Chinese population. Intern Med 49: 2385-2391, 2010.

13. Lubitz SA, Yin X, Fontes JD, Magnani JW, Rienstra M, Pai M, Villalon ML, Vasan RS, Pencina MJ, Levy D, et al: Association between familial atrial fibrillation and risk of new-onset atrial fibrillation. JAMA 304: 2263-2269, 2010.

14. Fox CS, Parise H, D'Agostino RB Sr, Lloyd-Jones DM, Vasan RS, Wang TJ, Levy D, Wolf PA and Benjamin EJ: Parental atrial fibrillation as a risk factor for atrial fibrillation in offspring. JAMA 291: 2851-2855, 2004.

15. Chen YH, Xu SJ, Bendahhou S, Wang XL, Wang Y, Xu WY, Jin HW, Sun H, Su XY, Zhuang QN, et al: KCNQ1 gain-offunction mutation in familial atrial fibrillation. Science 299: 251-254, 2003

16. Yang Y, Xia M, Jin Q, Bendahhou S, Shi J, Chen Y, Liang B, Lin J, Liu Y, Liu B, et al: Identification of a KCNE2 gain-offunction mutation in patients with familial atrial fibrillation. Am J Hum Genet 75: 899-905, 2004.

17. Olson TM, Michels VV, Ballew JD, Reyna SP, Karst ML, Herron KJ, Horton SC, Rodeheffer RJ and Anderson JL: Sodium channel mutations and susceptibility to heart failure and atrial fibrillation. JAMA 293: 447-454, 2005.

18. Hong K, Bjerregaard P, Gussak I and Brugada R: Short QT syndrome and atrial fibrillation caused by mutation in $\mathrm{KCNH} 2 . \mathrm{J}$ Cardiovasc Electrophysiol 16: 394-396, 2005.

19. Xia M, Jin Q, Bendahhou S, He Y, Larroque MM, Chen Y, Zhou Q, Yang Y, Liu Y, Liu B, et al: A Kir2.1 gain-of-function mutation underlies familial atrial fibrillation. Biochem Biophys Res Commun 332: 1012-1019, 2005. 
20. Gollob MH, Jones DL, Krahn AD, Danis L, Gong XQ, Shao Q, Liu X, Veinot JP, Tang AS, Stewart AF, et al: Somatic mutations in the connexin 40 gene (GJA5) in atrial fibrillation. N Engl J Med 354: 2677-2688, 2006.

21. Olson TM, Alekseev AE, Liu XK, Park S, Zingman LV, Bienengraeber M, Sattiraju S, Ballew JD, Jahangir A and Terzic A: Kv1.5 channelopathy due to KCNA5 loss-of-function mutation causes human atrial fibrillation. Hum Mol Genet 15: 2185-2191, 2006

22. Lundby A, Ravn LS, Svendsen JH, Hauns S, Olesen SP and Schmitt N: KCNE3 mutation V17M identified in a patient with lone atrial fibrillation. Cell Physiol Biochem 21: 47-54, 2008.

23. Ravn LS, Aizawa Y, Pollevick GD, Hofman-Bang J, Cordeiro JM, Dixen U, Jensen G, Wu Y, Burashnikov E, Haunso S, et al: Gain of function in IKs secondary to a mutation in KCNE5 associated with atrial fibrillation. Heart Rhythm 5: 427-435, 2008.

24. Hodgson-Zingman DM, Karst ML, Zingman LV, Heublein DM, Darbar D, Herron KJ, Ballew JD, de Andrade M, Burnett JC Jr and Olson TM: Atrial natriuretic peptide frameshift mutation in familial atrial fibrillation. N Engl J Med 359: 158-165, 2008.

25. Ren X, Xu C, Zhan C, Yang Y, Shi L, Wang F, Wang C, Xia Y, Yang B, Wu G, et al: Identification of NPPA variants associated with atrial fibrillation in a Chinese GeneID population. Clin Chim Acta 411: 481-485, 2010.

26. Zhang X, Chen S, Yoo S, Chakrabarti S, Zhang T, Ke T, Oberti C, Yong SL, Fang F, Li L, et al: Mutation in nuclear pore component NUP155 leads to atrial fibrillation and early sudden cardiac death. Cell 135: 1017-1027, 2008.

27. Watanabe H, Darbar D, Kaiser DW, Jiramongkolchai K, Chopra S, Donahue BS, Kannankeril PJ and Roden DM: Mutations in sodium channel beta1- and beta2-subunits associated with atrial fibrillation. Circ Arrhythm Electrophysiol 2: 268-275, 2009.

28. Wang P, Yang Q, Wu X, Yang Y, Shi L, Wang C, Wu G, Xia Y, Yang B, Zhang R, et al: Functional dominant-negative mutation of sodium channel subunit gene SCN3B associated with atrial fibrillation in a Chinese GeneID population. Biochem Biophys Res Commun 398: 98-104, 2010.

29. Thibodeau IL, Xu J, Li Q, Liu G, Lam K, Veinot JP, Birnie DH, Jones DL, Krahn AD, Lemery R, et al: Paradigm of genetic mosaicism and lone atrial fibrillation: physiological characterization of a connexin 43-deletion mutant identified from atrial tissue. Circulation 122: 236-244, 2010.

30. Brugada R, Tapscott T, Czernuszewicz GZ, Marian AJ, Iglesias A, Mont L, Brugada J, Girona J, Domingo A, Bachinski LL and Roberts R: Identification of a genetic locus for familial atrial fibrillation. N Engl J Med 336: 905-911, 1997.

31. Ellinor PT, Shin JT, Moore RK, Yoerger DM and MacRae CA: Locus for atrial fibrillation maps to chromosome 6q14-16. Circulation 107: 2880-2883, 2003.

32. Oberti C, Wang L, Li L, Dong J, Rao S, Du W and Wang Q: Genome-wide linkage scan identifies a novel genetic locus on chromosome $5 \mathrm{p} 13$ for neonatal atrial fibrillation associated with sudden death and variable cardiomyopathy. Circulation 110 3753-3759, 2004

33. Volders PG, Zhu Q, Timmermans C, Eurlings PM, Su X, Arens YH, Li L, Jongbloed RJ, Xia M, Rodriguez LM and Chen YH: Mapping a novel locus for familial atrial fibrillation on chromosome10p11-q21. Heart Rhythm 4: 469-475, 2007.

34. Hu DL, Chen FK, Liu YQ, Sheng YH, Yang R, Kong XQ, Cao KJ, Gu HT and Qian LM: GATA-4 promotes the differentiation of P19 cells into cardiac myocytes. Int J Mol Med 26 365-372, 2010

35. Bruneau BG. The developmental genetics of congenital heart disease. Nature 451: 943-948, 2008

36. Pikkarainen S, Tokola H, Kerkelä R and Ruskoaho H: GATA transcription factors in the developing and adult heart Cardiovasc Res 63: 196-207, 2004.

37. Wang J, Fang M, Liu XY, Xin YF, Liu ZM, Chen XZ, Wang XZ, Fang WY, Liu X and Yang YQ: A novel GATA4 mutation responsible for congenital ventricular septal defects. Int J Mol Med 28: 557-564, 2011

38. Liu XY, Wang J, Zheng JH, Bai K, Liu ZM, Wang XZ, Liu X, Fang WY and Yang YQ: Involvement of a novel GATA4 mutation in atrial septal defects. Int J Mol Med 28: 17-23, 2011.

39. Wang J, Xin YF, Liu XY, Liu ZM, Wang XZ and Yang YQ: A novel NKX2-5 mutation in familial ventricular septal defect. Int J Mol Med 27: 369-375, 2011
40. Gutierrez-Roelens I, De Roy L, Ovaert C, Sluysmans T, Devriendt K, Brunner HG and Vikkula M: A novel CSX/ NKX2-5 mutation causes autosomal-dominant AV block: are atrial fibrillation and syncopes part of the phenotype? Eur J Hum Genet 14: 1313-1316, 2006.

41. Boldt LH, Posch MG, Perrot A, Polotzki M, Rolf S, Parwani AS, Huemer M, Wutzler A, Ozcelik C and Haverkamp W: Mutational analysis of the PITX2 and NKX2-5 genes in patients with idiopathic atrial fibrillation. Int J Cardiol 145: 316-317, 2010.

42. Posch MG, Boldt LH, Polotzki M, Richter S, Rolf S, Perrot A, Dietz R, Ozcelik C and Haverkamp W: Mutations in the cardiac transcription factor GATA4 in patients with lone atrial fibrillation. Eur J Med Genet 53: 201-203, 2010.

43. Yang YQ, Wang MY, Zhang XL, Tan HW, Shi HF, Jiang WF, Wang XH, Fang WY and Liu X: GATA4 loss-of-function mutations in familial atrial fibrillation. Clin Chim Acta 412: 1825-1830, 2011

44. Jiang JQ, Shen FF, Fang WY, Liu X and Yang YQ: Novel GATA4 mutations in lone atrial fibrillation. Int J Mol Med 28: 1025-1032, 2011

45. Zhang Y, Rath N, Hannenhalli S, Wang Z, Cappola T, Kimura S, Atochina-Vasserman E, Lu MM, Beers MF and Morrisey EE: GATA and Nkx factors synergistically regulate tissue-specific gene expression and development in vivo. Development 134: 189-198, 2007.

46. Suzuki E, Evans T, Lowry J, Truong L, Bell DW, Testa JR and Walsh K: The human GATA-6 gene: structure, chromosomal location, and regulation of expression by tissue-specific and mitogen-responsive signals. Genomics 38: 283-290, 1996.

47. Lin X, Huo Z, Liu X, Zhang Y, Li L, Zhao H, Yan B, Liu Y, Yang $\mathrm{Y}$ and Chen YH: A novel GATA6 mutation in patients with tetralogy of Fallot or atrial septal defect. J Hum Genet 55: 662-667, 2010

48. Zheng GF, Wei D, Zhao H, Zhou N, Yang YQ and Liu XY: A novel GATA6 mutation associated with congenital ventricular septal defect. Int J Mol Med 29: 1065-1071, 2012.

49. Yang YQ, Wang XH, Tan HW, Jiang WF, Fang WY and Liu X: Prevalence and spectrum of GATA6 mutations associated with familial atrial fibrillation. Int J Cardiol 155: 494-496, 2012

50. Haïssaguerre M, Jaïs P, Shah DC, Takahashi A, Hocini M Quiniou G, Garrigue S, Le Mouroux A, Le Métayer P and Clémenty J: Spontaneous initiation of atrial fibrillation by ectopic beats originating in the pulmonary veins. N Engl J Med 339: 659-666, 1998

51. Mommersteeg MT, Brown NA, Prall OW, de Gier-de Vries C, Harvey RP, Moorman AF and Christoffels VM: Pitx 2c and $\mathrm{Nkx} 2-5$ are required for the formation and identity of the pulmonary myocardium. Circ Res 101: 902-909, 2007.

52. Mommersteeg MT, Christoffels VM, Anderson RH and Moorman AF: Atrial fibrillation: a developmental point of view. Heart Rhythm 6: 1818-1824, 2009.

53. Mommersteeg MT, Hoogaars WM, Prall OW, de Gier-de Vries C, Wiese C, Clout DE, Papaioannou VE, Brown NA, Harvey RP, Moorman AF and Christoffels VM: Molecular pathway for the localized formation of the sinoatrial node. Circ Res 100: 354-362, 2007.

54. Watanabe Y, Benson DW, Yano S, Akagi T, Yoshino M and Murray JC: Two novel frameshift mutations in NKX2.5 result in novel features including visceral inversus and sinus venosus type ASD. J Med Genet 39: 807-811, 2002

55. Pabst S, Wollnik B, Rohmann E, Hintz Y, Glänzer K, Vetter H, Nickenig $G$ and Grohé C: A novel stop mutation truncating critical regions of the cardiac transcription factor NKX2-5 in a large family with autosomal-dominant inherited congenital heart disease. Clin Res Cardiol 97: 39-42, 2008.

56. Gruver EJ, Fatkin D, Dodds GA, Kisslo J, Maron BJ, Seidman JG and Seidman CE: Familial hypertrophic cardiomyopathy and atrial fibrillation caused by Arg663His beta-cardiac myosin heavy chain mutation. Am J Cardiol 83: 13H-18H, 1999.

57. Yang YQ, Liu X, Zhang XL, Wang XH, Tan HW, Shi HF, Jiang WF and Fang WY: Novel connexin40 missense mutations in patients with familial atrial fibrillation. Europace 12: 1421-1427, 2010.

58. Yang YQ, Zhang XL, Wang XH, Tan HW, Shi HF, Jiang WF, Fang WY and Liu X: Connexin40 nonsense mutation in familial atrial fibrillation. Int J Mol Med 26: 605-610, 2010. 